\title{
Vinte anos sem Darcy: Impressões e notas ${ }^{1}$
}

\author{
Helena Bomeny - Universidade do Estado do Rio de Janeiro (UERJ)
}

\begin{abstract}
Resumo
Darcy Ribeiro foi presença constante em pesquisas que fiz. Foi do acervo do CPDOC da FGV que me aproximei intelectualmente daquele que seria o parceiro do qual Darcy não se separaria desde 1950. Ter-se aproximado de Anísio Teixeira produziu no antropólogo um verdadeiro roteiro de atuação pública e deu a ele o desenho de uma agenda onde o tema da educação ocupou lugar primordial. A provocação para escrita dessas notas veio da indagação sobre a falta que um intelectual como Darcy pode fazer. Em que ficamos mais pobres com a saída de cena deste intelectual público e político engajado? Discuto cinco aspectos: aposta no Brasil como sociedade; aposta na política como meio de realização humana; capacidade crítica que distanciou Darcy de fidelidade intransigente a princípios imobilizadores; eleição do popular como sujeito da nação; paixão pela literatura como expressão maior da criatividade, da produção intelectual e científica, da ação política, e da afetividade e dos sentimentos.
\end{abstract}

Palavras-chave: sociedade; política; povo; educação

\section{Twenty years without Darcy: impressions and notes}

\begin{abstract}
Darcy Ribeiro was always present in researches I did. In the Fundação Getúlio Vargas' CPDOC acquis I got intellectually closer to Anísio Teixeira, Darcy Ribeiro's partner since 1950 until the end of his life. The relationship between Anisio Teixeira and Darcy Ribeiro made such an impact on the anthropologist that he developed a true guide for public performance and gave him an agenda design where education was the main theme. The mobilization for writing these notes came from the question about how much the lack of an intellectual as Darcy can do. How poor we become without the presence of this public intellectual and engaged politician? I discuss five aspects: bet on Brazil as a society; bet in politics as a means of human achievement; critical capacity that distanced Darcy from uncompromising loyalty to immobilizer principles; election of the people as fellow of the nation; passion for literature as larger expression of creativity, of intellectual and scientific production, of political action, and of affection and feelings.
\end{abstract}

Keywords: society; politics; people; education

\section{Vinte anos sem Darcy: Impressões e notas}

O momento em que vivemos neste 2017 tem provocado uma espécie de homogeneidade valorativa que, a meu juízo, é perturbadora. Não tenho tido registro de alguém, pela esquerda ou direita, de geração mais nova ou mais velha, escolarizado ou sem instrução que fale do Brasil em alguma chave de otimismo. O otimismo se transformou em uma espécie de prescrição médica por aqueles que, na condução de alguma política, precisa acreditar ou fazer acreditar na eficácia de remédios que estão em teste. Um tempo estranho que nas lúcidas palavras de Zigmunt Bauman 
está nos exigindo mais reflexão do que informação. É como se o volume excessivo de informações com que somos bombardeados nos mais díspares veículos de comunicação nos afogasse e nos dificultasse o exercício reflexivo. Inevitável, além de Bauman, a lembrança de Norbert Elias com seus alertas sobre o nem sempre progressivo processo civilizador. A desconcertante combinação de um movimento evolutivo de conquistas com atitudes associadas ao estágio de barbárie, ou seja, de incivilização nos atropela contemporaneamente. Para onde estamos indo, o que vai sobrar do que se conquistou e como recuperar o que se perdeu, como voltar a um trilho de razoabilidade, ainda que não consensual, são inquietações de um diagnóstico desconfortante.

O Brasil passou por transformações sensíveis nos últimos vinte anos, entrou no noticiário com informações pouco usuais por indicadores positivos como taxa pequena de desemprego, maior distribuição de rendas, volume considerável de ingresso de pessoas nas distintas esferas de formação educacional (fundamental, médio e superior), ampliação da capacidade de consumo, deslocamentos progressivos em direção a bens materiais e simbólicos que ainda não haviam sido disponibilizados para uma grande maioria da sociedade etc. Criou-se inclusive uma categoria sobre a qual os sociólogos depositaram desconfiança imediata - "a nova classe média" - sugerindo que setores até então excluídos da sociedade haviam, finalmente, experimentado mobilidade social ascendente. O início do segundo mandato da presidente Dilma Roussef, em 2015, no entanto, foi também o início de uma reversão completa não apenas de expectativas, mas de alteração da maneira como o Brasil passou a ocupar o noticiário nacional e internacional. Foi nessa quadra de reversão de expectativas, de sentimentos controvertidos que recebi o convite de celebrar Darcy Ribeiro a propósito de seus vinte anos de ausência, de 1997 a 2017. Muitas das questões levantadas, discutidas e registradas por ele em distintos formatos de comunicação foram, de alguma maneira, testadas com os sinais de alteração nos indicadores de inclusão. Voltarei a este ponto mais adiante.

Darcy foi presença constante em alguns esforços de pesquisa que fiz desde o contato com o ministério Gustavo Capanema (1934-1945). Foi do acervo depositado no CPDOC da Fundação Getúlio Vargas que me aproximei intelectualmente daquele que seria o parceiro do qual Darcy não se separaria desde a década de 1950, e que marcou profundamente sua própria agenda pública de ação política, trabalho e produção intelectual. Ter-se aproximado de Anísio Teixeira (1900-1971) foi mais do que a ventura da aproximação entre dois amigos: produziu no antropólogo um verdadeiro roteiro de atuação pública e deu a ele o desenho de uma agenda onde o tema da educação ocupou lugar primordial. “Anísio me ensinou a duvidar e a pensar”, lembraria Darcy em seu livro de memórias, Confissões. 
Tratei desse encontro no livro Darcy Ribeiro, a Sociologia de um indisciplinado, mas em outros textos também quando o que me movia era o interesse pela educação pública brasileira. (Bomeny, 2001a e 2001b) Anísio, americanista, urbano, envolvido com os problemas da educação e com a universalização desse direito, era uma das lideranças mais notáveis do Movimento dos Pioneiros da Educação Nova - que arregimentou intelectuais na década de 1920 nas caravanas pelo Brasil em favor de reformas educacionais e sanitárias. Darcy, àquela altura mobilizado pela questão indígena, (herança de sua aproximação com o marechal Cândido Rondon), adentrava o interior brasileiro em busca do que supunha traduzir a alma nacional. Olhava com desconfiança o que considerava uma educação comunitária, preconizada na América do Norte, fruto da cultura protestante, que obrigava aos fiéis a leitura da bíblia, situação em nada comparável com o Brasil. A aproximação entre esses dois personagens alterou neles mesmos suas próprias convicções de origem. Darcy aprendeu a valorizar a experiência norte-americana a ponto de afirmar, em resposta aos ataques que sofria na condução do Programa Especial de Educação, serem os CIEPs uma escola pública regular como as que os norte-americanos criaram. Percorreram juntos uma estrada repleta de iniciativas que deixaram marcas profundas na cultura brasileira. $\mathrm{O}$ encontro aconteceu no Instituto Nacional de Estudos Pedagógicos (INEP), criado por Anísio, de onde nasceria o Centro Brasileiro de Pesquisas Educacionais (CBPE), que contou com a participação ativa de Darcy $^{2}$.

A parceria se afinou na criação da Universidade de Brasília (UnB), na abertura dos anos 1960 e foi consolidada quando Darcy Ribeiro assumiu o Ministério da Educação e Cultura (MEC) em setembro de 1962, sendo substituído por Anísio Teixeira na reitoria da UnB. Permaneceu no ministério até 23 de janeiro de 1963, quando assumiu a chefia do Gabinete Civil da Presidência da República no governo João Goulart. O golpe de 1964 retirou o antropólogo não só do governo João Goulart (de quem era chefe da Casa Civil) como da Universidade do Brasil, Rio de Janeiro, onde lecionava desde 1956. Para não falar, claro, da própria UnB, invadida e torpedeada pelas forças da repressão militar. (Bomeny, 2016)

O Brasil perdeu Anísio Teixeira precocemente. A morte abrupta, em 1971, alcançou Darcy no exílio. Ao retornar ao Brasil definitivamente, em 1978, ele reiniciou a cruzada pelo ensino básico, e cultivou ao longo de sua vida o patrimônio herdado da união com o renovador da educação no Brasil. Foi por ocasião da morte de Darcy, em fevereiro de 1997, que tomei contato com a impressão forte de ter sido ele o último expoente da Escola Nova - não por ter feito parte do movimento dos Pioneiros, mas por ter empunhado a bandeira dos educadores que lideraram a jornada pela defesa do ensino público, laico, gratuito e obrigatório: dever do Estado; direito cívico dos cidadãos. Estou segura de que se deveu ao encontro com Anísio a devoção apaixonada por um Revista Interinstitucional Artes de Educar. Rio de Janeiro, V. 3 N.2 - pag 22-30 (jul/out2017): "Número Esperial Darcy Ribeiro" DOI: $10.12957 /$ riae.2017.31707 
programa de educação capitaneado pelo governador Leonel Brizola nos dois governos do Rio de Janeiro (1983-1987; 1991-1994). Era chegada a hora de realizar a utopia escolanovista na escrita de uma reforma educacional com profundos impactos no Rio de Janeiro. O Rio, modelo para o país, espelho e caixa de ressonância de inovações e ousadias, poderia ser a matriz da universalização no país de um programa extensivo de educação de qualidade para todos.

Em 1982, Darcy elegeu-se vice-governador do Rio de Janeiro pelo Partido Democrático Trabalhista (PDT), na chapa encabeçada por Brizola. A convivência com Brizola mesclou a paixão pela educação, herdada de Anísio, com o que Darcy chamou de "apreço pela classe de baixo". Um discurso popular embasado não mais nas Minas Gerais, sua terra de origem, mas na tradição riograndense, cujas linhas estavam traçadas na trajetória política que veio com Vargas, passando por João Goulart e Brizola.

O Programa Especial de Educação e os CIEPs ganharam seu curso. Já foram matéria de reflexão não apenas nem principalmente minha, mas, ao contrário, parte do acervo de pesquisas sobre educação no Brasil. (Mignot, 1988; Emerique, 1997; Bomeny, 2001, 2008). Conhecemos seus objetivos divulgados à profusão: garantir à população o direito a um ensino gratuito moderno, reestruturado do ponto de vista pedagógico e tecnologicamente aparelhado com a previsão de metas assistenciais (como uniformes, calçados e melhoria da qualidade da merenda) e pedagógicas (como aumento da carga horária diária para cinco horas e revisão de todo o material didático), treinamento dos professores e melhoria de suas condições de trabalho, reforma e conservação das escolas e do mobiliário, além de novos projetos educacionais - voltados à pré-escola, à criação de Centros Culturais Comunitários e à educação juvenil noturna. Havia entre os idealizadores a convicção de que a democratização da educação teria que minimizar as carências essenciais daqueles estudantes que provinham de situações sociais desprotegidas.

Os cuidados se estendiam à montagem de bibliotecas, salas de estudo e espaços de lazer com profissionais treinados para a jornada de tempo integral. Como parte da estrutura física do prédio, previam-se dormitórios para abrigar "pais sociais" que se responsabilizariam, em troca da moradia, pelo acompanhamento escolar de crianças que também morassem nas escolas. A fala de Darcy sobre o projeto deixa clara a convicção que o norteou:

Ao invés de escamotear a dura realidade em que vive a maioria de seus alunos, proveniente dos segmentos sociais mais pobres, o CIEP compromete-se com ela para poder transformá-la. É inviável educar crianças desnutridas? Então o CIEP supre as necessidades alimentares dos seus alunos. A maioria dos alunos não tem recursos financeiros? Então o CIEP fornece gratuitamente os uniformes e o material escolar necessário. Os alunos estão expostos a doenças infecciosas, estão com problemas dentários ou apresentam deficiência visual ou auditiva? Então o CIEP proporciona a todos eles assistência médica e odontológica. (RIBEIRO, 1994, P. 14) 
Durante os oito anos dos dois governos Brizola (1983-1987; 1991-1994) o programa ergueu 507 CIEPs e alcançou uma repercussão pública pouco comum em assuntos educacionais. A figura política do governador e a personalidade apaixonada, e nem sempre ponderada do vice, a marcha frenética com que os CIEPs eram construídos e a confecção de um programa complexo implantado por meio de uma secretaria extraordinária de Educação despertaram simultaneamente adesões e reações críticas, vindas de diferentes extrações da comunidade intelectual e das hostes políticas adversárias. Uma intervenção pedagógica completamente ungida na esfera política criou mal-estar na comunidade dos educadores. O argumento era que o Programa Especial de Educação havia se transformado em programa político, em detrimento da melhoria do sistema educacional.

Mas os dissabores o estimulavam na defesa do ideal que abraçara. A cada matéria crítica contrapunha-se a voz de Darcy Ribeiro, sustentando a continuidade no tratamento de uma escola pública que até aquele momento, no Brasil, estava longe de cumprir o papel que a ela deve ser atribuído em uma sociedade democrática. A reação veio de muitos segmentos da sociedade: educadores expunham os pontos de fragilidade do Programa que já nascia como programa de massa, extenso, volumoso, caro e sem condições de funcionamento na medida e na velocidade com que se implantava. Dos cientistas sociais explodiam avaliações sobre os efeitos negativos para a democracia do populismo implicado na política pública assistencialista do governo Brizola, qualificado como personalista, voluntarista, demagógico, inconsequente. (Bomeny, 2008)

O acúmulo de críticas por atores qualificados, e em muitos pontos, justificáveis, favoreceu, a meu ver, a falta de reação ao brusco e irresponsável desmonte do programa pelo governo seguinte de Wellington Moreira Franco. Os CIEPs foram desmontados como estruturas de ensino em horário integral, e as construções foram interrompidas. A rede pública voltaria ao sistema convencional, agora com o ensino fundamental municipalizado.

Mas a provocação para escrita dessas notas veio da indagação sobre a falta que um intelectual como Darcy pode fazer. Portanto, sobre o patrimônio que se pode atribuir a um personagem como Darcy Ribeiro. E em sintonia com o sentimento da abertura deste texto, prossigo com o que talvez, a meu juízo, simbolize a expressão falta. Em que ficamos mais pobres com a saída de cena de um intelectual público e um político engajado como Darcy Ribeiro?

1. A aposta no Brasil como sociedade, como projeto humano, como criação baseada na mistura, na capacidade de interação de culturas tão distintas como as que aqui se mesclaram desde a chegada dos portugueses. A força de um país como o Brasil vem, na conviç̧ão de Darcy, dessa mistura, ao contrário de muitos diagnósticos que atribuem a ela nossa fragilidade e incompletude como nação civilizada. De igual 
maneira e com igual vigor defendia a herança ibérica como parte substancial do que a cultura brasileira poderia exibir de melhor em tolerância, capacidade de interação, convivência com diferenças. A paixão pelo Brasil em sua profunda compreensão foi o que moveu sua vida intelectual, afetiva e política. Este talvez seja um dos pontos que mais singularizaram a trajetória do intelectual. A compreensão do país seria o primeiro passo para a proposição de alternativa ou projeto de nação. Darcy não se furtou ao mergulho tanto na produção intelectual brasileira que digeriu compulsivamente, como com as manifestações nativas de grupos culturais indígenas que modelaram o projeto de nação ainda que excluídos dele por processos continuados de expulsão. Os habitantes das florestas e seus ensinamentos ocuparam a imaginação antropológica de Darcy e Berta Ribeiro atravessando a escrita, sendo recuperados como ingredientes fundamentais para explicar o que se tornaria o país tal como se constituiu. $O$ antropólogo tratou os índios como parte integrante do projeto nacional e não como contingentes isolados, distantes e destacados da população brasileira, menos ainda, como adereço e decoração no inventário da cultura nacional.

2. A aposta na política como meio de realização humana. Política como vocalização de interesses, expressão pública de valores e vocações nacionais. Este foi um ponto que respondeu pela força de Darcy como intelectual, mas também que revelou em muitas dimensões sua fraqueza. A expressão pública do comprometimento da razão com a política foi configurada em Darcy Ribeiro como convicção de seu lugar na sociedade pela política. Proferia em seus discursos a conclamação do intelectual para suas responsabilidades públicas. $\mathrm{O}$ engajamento de que era revestido em suas aventuras políticas e sociais era uma exigência que dirigia aos que se aventurassem pelo universo intelectual. O contrário, em suas palavras, era o intelectual alienado, distanciado das condições singulares de seu país, que se movia por um condenável entrincheiramento em verdadeiras torres de marfim. Tal exposição provocou reações críticas ao estilo cultivado de um intelectual apaixonado e iracundo, insubordinado e inconstante, movido por vaidade e excessivo individualismo que punham em risco o rigor intelectual e o que se espera em processos racionais de institucionalização. Faltava-lhe talvez o conjunto de atributos que tão bem se encaixavam na ideologia da mineiridade, sendo ele próprio um mineiro: prudência, constância, perseverança, moderação, previsibilidade...

3. A capacidade crítica que o distanciou de qualquer fanatismo ou fidelidade intransigente a princípios de ação imobilizadores. Este talvez tenha sido o traço que mais lhe tenha 
cobrado em vida. Não poupou polêmica com parceiros, adversários, filiados de associações às quais pertenceu, membros das comunidades científicas das quais participou ou às quais aderira. Em exercício de imaginação sou capaz de visualizar a impetuosidade com que estaria se interpondo hoje, em 2017, no debate sobre a reforma do ensino médio, os caminhos do ensino superior, confrontando facções as mais diversas, protagonistas e antagonistas, criando dissabores e fecundando brechas com provocações fundadas e inusitadas.

4. A eleição do popular como sujeito da nação. Entre os traços característicos do estilo de liderança de Darcy Ribeiro talvez este seja um dos mais acentuados. E provavelmente um dos que o singularizaram. A crítica profunda que Darcy formulou a respeito da elite brasileira fortaleceu, sem dúvida, sua convicção de que no popular seria possível encontrar um sentido de nacionalidade mais próximo do que representaria o Brasil em sua essência. A ideia de que o povo é capaz de conduzir seu destino, fazer escolhas e representar culturalmente o país atravessou seus escritos, vários de seus depoimentos e encontrou ressonância expressiva em seu encontro com Leonel Brizola. Valorizou a singularidade positiva brasileira pela mistura de povos em cruzamentos continuados - capacidade dos portugueses em se acasalar com índios e negros. A convicção de que no popular reside a matéria constitutiva da formação do projeto nacional não encontraria abrigo em uma cultura elitista, seletiva e excludente como a que vigorou no país.

5. Por último, e talvez mais importante, a paixão pela literatura como expressão maior da criatividade, da produção intelectual e científica, da ação política, e naturalmente, da afetividade e dos sentimentos. Literatura como alimento de seu agudo senso de humor. Darcy apossava-se da tradição literária brasileira e latino-americana, especialmente, e por meio delas, aprofundava sua paixão pelo Brasil e sua interlocução com os países irmãos. Há profundo aprendizado do sentido maior de nacionalidade com a ficção pontificava nosso personagem. De todas as faltas, talvez seja esta a que mais nos afeta em dias de descrença e tamanha turbulência. Em dias em que o mundo dos interesses mais egoístas parece se expandir de forma incontrolável. Darcy acreditava que pela literatura seria possível alargar nossa capacidade de compreensão, de transigência e tolerância. O mergulho na cultura nacional teve no transporte da literatura o meio mais sensível de adentrar os meandros do que nos fazia parte de contexto maior - europeu e latino-americano - e do que nos singularizava em nossas próprias maneiras dinâmicas de interagir. Foi o que, em grande medida, propiciou a crítica ao dogmatismo tão 
presente nos discursos e nos textos que produziu. Sua recusa à institucionalização das Ciências Sociais que pressupunha regulamentação, previsibilidade, racionalização de procedimentos em parte é explicada por seu temperamento intemperante, mas em parte também, pela avaliação negativa que tinha da estreiteza implicada em uma separação canônica entre ciência e literatura, academia e o mundo dos sentimentos. A literatura em Darcy Ribeiro foi mais que fruição. Significou instrumento de interpretação da realidade, sem o qual, certamente sua métrica de interferência intelectual teria outra conformação. A recepção de sua obra em contexto externo, como tão bem apontou Haydée Ribeiro Coelho, provocou nos intelectuais das letras impacto produtivo no sentido de reorientação dos próprios eixos analíticos que desenvolviam. É como nos apresenta:

...Talvez o inovador do pensamento de Darcy tenha desconcertado muitos de seus colegas, incluídos - ou melhor dito, principalmente - os brasileiros. Isso fez que não se atendesse às autênticas possibilidades que suas exposições ofereciam. Atrevo-me a dizer que onde mais profundamente atingiu foi na Argentina, e acaso tenha influído para eles o fato de que As Américas e a civilização veio à luz antes que outros trabalhos de Darcy, em Buenos Aires e em uma editora muito popular e de grande distribuição. Esse vestígio se notou mais que entre outros, em intelectuais formados nas Letras - como Adolfo Colombres, por exemplo - que a partir do conhecimento da obra de Darcy, se inclinaram para o amplo campo da Antropologia e dos estudos culturais. Para muitos argentinos, o pensamento de Darcy foi um verdadeiro deslumbramento. (Coelho,2005:170)

Esse homem das letras que adentrou a Antropologia e se fez publicamente conhecido por uma atuação política com alta carga de mobilização deixou seus rastros. A inconstância na execução de programas e projetos com os quais se envolveu, a intemperança com que se movia nas rotinas funcionais, e o estilo personalista que impunha aos processos de decisão e de formulação de políticas deram munição a muitas das críticas de que foi alvo como intelectual público e gestor político. Mas o comprometimento com o Brasil, a imaginação incessante e o entusiasmo que derramava em cada nova ideia intelectual ou iniciativa social são a medida mais visível da falta que os vinte anos de ausência nos trazem.

\section{Bibliografia:}

BAUMAN, Zygmunt. Entrevista. In Tempo social, vol.16 nº.1 São Paulo Jun. 2004. http://www.scielo.br/scielo.php?script=sci_arttext\&pid=S0103-20702004000100015

BOMENY, Helena. Darcy Ribeiro. Sociologia de um indisciplinado. Belo Horizonte, Editora da UFMG, 2001a.

BOMENY, Helena. Intelectuais da educação. Rio de Janeiro, Jorge Zahar Editor, 2001b. 
BOMENY, Helena. "Salvar pela escola: Programa Especial de Educação". Em: Marieta de Moraes Ferreira (organizadora) A força do povo: Brizola e o Rio de Janeiro. Rio de Janeiro: Alerj, PDOC/FGV, 2008, p.95-127.

BOMENY, Helena. "Universidade de Brasília: filha da utopia de reparação". Sociedade e Estado. UnB impresso. Brasília, vol. 31, série 1, 2016, p.1003-1028.

COELHO, Haydée Ribeiro. “A cultura na perspectiva de Darcy Ribeiro e Ángel Rama”. Via Atlântica, n.8, Dez/2005, p.165-183.

ELIAS, Norbert. A sociedade dos indivíduos. Rio de Janeiro: Jorge Zahar Ed. 1994.

EMERIQUE, Raquel Balmant. "Do salvacionismo à segregação: a experiência dos Centros Integrados de Educação Pública do Rio de Janeiro". [Dissertação de mestrado defendida no Programa de Pós-Graduação em Ciências Sociais (PPCIS) da UERJ], 1997.

MIGNOT, Ana Chrystina Venancio. CIEP - Centro Integrado de Educação Pública: alternativa para a qualidade do ensino ou nova investida do populismo na educação? Rio de Janeiro, 1988. Dissertação (mestrado), PUC-RJ.

. CIEP - Centro Integrado de Educação Pública: alternativa para a qualidade do ensino ou nova investida do populismo na educação? Em Aberto, n. 44, p. 45-63, 1989.

. A escola pública e a construção de um espaço alternativo de educação. Educação e Sociedade, n. 40, p. 502-508, 1991

- Decifrando o recado do nome: uma escola em busca de sua identidade pedagógica. Revista Brasileira de Estudos Pedagógicos, v. 74, n. 178, p. 619-638, 1993. Brasília, INEP/MEC.

RIBEIRO, Darcy. Confissões. São Paulo: Companhia das Letras, 1997.

. O estado da educação in GABINETE DO SENADOR DARCY RIBEIRO, Carta 12. Brasília: Senado Federal, 1994, p. 11-22

XAVIER, Libânia. O Brasil como laboratório: educação e ciências sociais no projeto do Centro Brasileiro de Pesquisas Educacionais CBPE/INEP/MEC (1950/1960). Bragança Paulista: IFAN/CDAPH/EDUSF, 1999

\footnotetext{
1 Este texto foi apresentado pela autora na mesa redonda Darcy semeia escolas no Seminário Darcy Ribeiro - 20 anos. Que falta ele nos faz!, promovido pela Fundação Darcy Ribeiro, em parceria com o Arquivo Nacional e a Academia Brasileira de Letras em fevereiro de 2017.

${ }^{2}$ Ver sobre a experiência do CBPE o trabalho de Libânia Xavier, 1999
} 